\title{
The Frequency and Typing of Human Papilloma Virus Among Women with Normal and Abnormal Cytology in Southern Khorasan, Eastern
}

\section{Iran}

\author{
Davod Javanmard, ${ }^{1}$ Mohammad Hasan Namaei, ${ }^{1,}{ }^{*}$ Fatemeh Haghighi, ${ }^{2}$ Masood Ziaee, ${ }^{1}$ Mahmoodreza \\ Behravan, ${ }_{1}^{1}$ Jamal Mirzaei, ${ }^{3}$ Nahid Ghanbarzadeh, ${ }^{4}$ Zohreh Khazaei, ${ }^{4}$ Mahboobeh Zangoie, ${ }^{4}$ Narges \\ Naseh, ${ }^{4}$ Marzieh Ataei, ${ }^{4}$ Gholamreza Sharifzadeh, ${ }^{1}$ Alireza Salehabadi, ${ }^{1}$ and Malaknaz Ghannadkafi ${ }^{5}$ \\ ${ }^{1}$ Infectious Diseases Research Center, Birjand University of Medical Sciences, Birjand, Iran \\ ${ }^{2}$ Department of Pathology, Birjand University of Medical Sciences, Birjand, Iran \\ ${ }^{3}$ Infectious Disease Research Center, Aja University of medical sciences, Tehran, Iran \\ ${ }^{4}$ Department of Gynecology, Birjand University of Medical Sciences, Birjand, Iran \\ ${ }^{5}$ Faulty of Nursing and Midwifery, Birjand University of Medical Sciences, Birjand, Iran \\ "Corresponding author: Mohammad Hasan Namaei, Infectious Diseases Research Center, Birjand University of Medical Sciences, Ghafari Ave, Birjand, IR Iran. Tel/Fax: \\ +98-5632433004, E-mail: mhnamae@hotmail.com
}

Received 2016 October 19; Revised 2017 February 07; Accepted 2017 February 26.

\begin{abstract}
Background: Infection by certain types of human papilloma virus (HPV) is known as a causal and essential factor for cervical cancer, the second most common malignancy in women around the world.

Objectives: The aim of this study was to determine the frequency and types of HPV among women with normal and abnormal cytology in Southern Khorasan, eastern Iran.

Methods: This was a cross-sectional study with 253 randomized Pap smear samples from women who were referred to gynecologist clinics. Human papillomavirus-DNA testing (a nested PCR with primers MY09/ MY11 and GP5 +/ GP6 +) was performed on Pap smear samples. The first round PCR product was subjected for sequencing to determine the HPV types. Phylogenic analysis with Mega 6 was carried out to determine the relationship between HPV types.

Results: The mean age of patients were $34.47 \pm 5.38$ years; $85.77 \%$ with normal cytology, and the rest were with an abnormality; atypical cells of undetermined significance (ASCUS) and Low-grade squamous intraepithelial lesions (LISL). Human papilloma virusDNA was detected in $18.57 \%$ of population (15.66\% of normal and $36.11 \%$ of abnormal group) with the most prevalent HPV types 6 and 11. The HPV type 84 was identified in a case.

Conclusions: The result of this study revealed a partially high prevalence of HPV in women with normal cytology which are high risk for transmission in population. It is suggested that HPV testing should be carried out along with Pap test in screening programs to enhance early detection of neoplasia and intended infections.
\end{abstract}

Keywords: Human Papillomavirus, Genotyping, Pap Smear, Cervical Cancer, Southern Khorasan, Iran

\section{Background}

Cervical cancer is the second cause of cancer related deaths among women worldwide (1). Despite the screening programs that have been introduced to reduce the mortality and morbidity of the disease, it is estimated that 500,000 cases occur annually and that $50 \%$ cases lead to death worldwide (2). Today, it has been proved that the etiologic cause of cervical cancer is the human papilloma virus (HPV) (3); a double stranded DNA virus belonging to the Papillomaviridae family with more than 100 types (4). Human papilloma virus include high risk types $(16,18,31$, $33,35,39,45,51,52,56,58,59,68,73$, and 82 ) and low risk (6, 11, 40, 42, 43, 44, 54, 61, 70, 72, 81, and CP6108); types 26 ,
53, and 66 are classified as potential high risk, which can be transmitted via sexual contact (5).

Human papilloma virus types 6 and 11 are common low risk types that mostly lead to benign lesions such as common warts and low grade pre- malignancies (6). Furthermore these types can cause to anogenital warts and recurrent respiratory papillomatosis. High risk types of HPV, oncogenic types, including 16 and 18 are the leading cause of cervical and other anogeital cancers (7). It has been proved that women infected with high risk HPV types are at a higher risk of developing cervical neoplasia than those not infected with any HPV types or are infected with low risk HPV type (8). Most HPV infections are transient with spontaneous recovery and only a minor portion of infec- 
tions remain persistent leading to cervical intraepithelial neoplasia and invasive cancer (9).

Papanicolaou smear is an un-invasive safe method that can be used to detect all grades of cervical intra epithelial neoplasia (CIN) (10). Sensitivity of Pap smear test ranges from $30 \%-87 \%$ and its specificity ranges from $86 \%$ to $100 \%$ (11). Due to the fact that HPV has been identified as an etiologic agent of cervical cancer, HPV DNA testing as an adjuvant to Pap cytology test is a promising alternative or complementary test to enhance the effectiveness of cervical screening and presumably cost-effective, depending on screening interval (12). Since women with or without normal cytology while infected with high-risk HPV types 16 and 18 show a higher rate of progression to malignancy (13), detecting this sub-clinical or asymptomatic oncogenic $\mathrm{HPV}$ infection is very necessary in checking its progression to neoplasia and invasive cancer (14).

Human papilloma virus vaccines are now available in order to prevent most common oncogenic HPV types 16 and 18. Awareness of baseline population-based epidemiology and genotype distribution of HPV is necessary as a reference data for assessing the effectiveness of prophylactic HPV vaccines on HPV infection after administering vaccination (15). Human papilloma virus 16 is the most common type of HPV all over the world (16); however, the distribution of other types of HPV in different geographical areas is somewhat distinct. So determining HPV types in clinical setting is regarded as a vital diagnostic tool for cervical cancer, and also gives necessary information for the prevention and treatment of cervical cancer.

\section{Objectives}

Currently, no epidemiological data regarding HPV infection and genotype distribution have been reported in Southern Khorasan, which is one of the largest cities in east of Iran. The aim of this study was to determine the frequency and types of HPV among women subjected to routine Pap smear test in Southern Khorasan, east of Iran.

\section{Methods}

\subsection{Patients and Samples}

This was a research project approved by the ethical committee of Birjand University of Medical Sciences (the code number: 1393-12-07). Between September 2014 and December 2015, women aged 18 - 65 years attending routine cervical cancer screening at a center participated in this cross-sectional study. Two hundred and fifty three (253) samples were collected from women admitted at various pathological labs of Birjand who were subjected to gynecological examination by gynecologists. The epidemiologic and cytologic data were given from Dr. Haghighi pathologic lab, and was used in the study.

\subsection{Extraction of DNA}

Immediately after cytology test on the same day, the remaining contents in the vial were subjected to nucleic acid isolation by DNA extraction kit (Bionear, South Korea) according to manufacturer's instructions. In order to ensure the accuracy of DNA separation, concentrations of all DNA samples were determined by a NanoDrop 1000 Spectrophotometer. For internal control of extraction the $\beta$ globin gene was selected and a PCR test was performed with a pair of primer as previously discussed (17). Afterwards, positive cases were selected for HPV DNA detection.

\subsection{PCR Amplification of L1 Gene}

A nested PCR method was utilized in order to increase the sensitivity of HPV-DNA detection from epithelial cells shedding from endocervix. The primers MY09/MY11 (as outer) and GP5 +/GP6 + (as inner) primers (Table 1) were utilized for detecting the HPV L1 gene $(18,19)$. These primers are common- use consensus degenerate nucleotides designing so that targeted at a much conserved segment of L1 gene of viral capsid and detecting all HPV types.

Both outer and inner PCR reactions were carried out in a total content of $50 \mu \mathrm{L}$ containing $100 \mathrm{ng}$ of DNA extracted from Pap smears, 45 mM-KCl, 20 mM Tris-HCl pH 7.5, 100 $\mu \mathrm{M}$ of each dNTP, $5 \mathrm{mM} \mathrm{MgCl}_{2}, 1 \mathrm{U}$ Taq polymerase (YTA Taq, Yekta tajhiz, Iran) and 20 pmol of each primers. To perform the first-PCR step, $3 \mu$ l of DNA (20 to $450 \mathrm{ng}$ ) was utilized as target DNA (outer reaction); for the second step of amplification, $3 \mu \mathrm{L}$ of the first PCR product was utilized as template for amplification of DNA (inner reaction).

Thereafter, for the first round of amplification using MY sets there was a first denaturation temperature of $94^{\circ} \mathrm{C}$ for 5 minutes, followed by 30 cycles each consisting of $94^{\circ} \mathrm{C}$ for 30 seconds, $56^{\circ} \mathrm{C}$ for 30 seconds, and $72^{\circ} \mathrm{C}$ for 45 seconds. The final elongation step was carried out for $5 \mathrm{~min}$ utes to ensure the production of full-length amplicons. A same thermal program was used for nested round using GP primer pairs, except the annealing temperature that changed to $48^{\circ} \mathrm{C}$ and also the time of extension decreased to 30 seconds.

After electrophoresis, the visualization of positive samples were performed in a gel doc device under ultra violate radiation. Preparation of samples before and after the polymerase chain reactions were achieved in completely separated rooms to prevent contamination by previous PCR products. The extract of HeLa cell line was utilized 
Table 1. The Sequences and Target Gene of Primers Were Utilized in This Project

\begin{tabular}{|c|c|c|c|c|}
\hline Primer & Sequence & Target & Product size & Reference \\
\hline MY11 & GCMCAGGGWCATAAYAATGG ${ }^{\mathrm{a}}$ & HPV-L1 & 451 & Manos et al. (18) \\
\hline MYo9 & CGTCCMARRGGAWACTGATC ${ }^{\mathrm{a}}$ & $”$ & & \\
\hline GP5+ & TTTGTTACTGTGGTAGATAC & $”$ & 140 & Snijders et al. (19) \\
\hline GP6+ & GAAAAATAAACTGTAAATCA & $"$ & & \\
\hline Beta1 & TCAACCCTACAGTCACCCAT & $\beta$-globin & 501 & R.J. Nobre et al. (17) \\
\hline Beta2 & CTAACAATTACGAACAGCAATGAG & $”$ & & \\
\hline
\end{tabular}

${ }^{a}$ Mixed bases: $\mathrm{R}(\mathrm{A}, \mathrm{G}), \mathrm{Y}(\mathrm{C}, \mathrm{T}), \mathrm{M}(\mathrm{A}, \mathrm{C}), \mathrm{W}(\mathrm{A}, \mathrm{T})$

as positive control while a confirmed negative specimen along with sterile water were used as negative control.

\subsection{Genotyping}

Positive HPV DNA PCR samples were thereafter analyzed for determining the HPV genotypes. Human papilloma virus genotyping was performed by analyzing the sequence of first PCR product as it gives an eligible size of L1 gene for genotyping and phylogenic analysis. In order to determine the exact sequence of each isolate, the specimens were sent to Bionear Company, South Korea for direct bidirectional sequencing utilizing both forward and reverse outer primers (BigDye ${ }^{\mathrm{TM}}$ terminator cyclic sequencing and $\mathrm{ABI}$ 3730XL DNA analyze).

The sequences obtained were aligned with reference isolate sequences of all types and blast was carried out for each sequence. Further analysis was carried out on isolated sequences along with type specific reference sequences in Mega software (MEGA version 6; Tamura, Stecher, Peterson, Filipski, and Kumar 2013) to determine the phylogenic tree.

\section{Results}

\subsection{Baseline Population Characteristics}

A total of 253 women aged 18 - 65 years old were enrolled in this study. The brief clinical and epidemiological data of patients are given in Table 2 . The mean age of patients was $34.47 \pm 5.38$, those with normal cytology were 217 cases (85.77\%) and there were 36 cases with an abnormality (14.22\%); among them 21 cases (58.3\%) had a atypical cells of undetermined significance (ASCUS) result and 15 cases (41.6\%) had low- grade squamous intraepithelial lesions (LSIL) result. In this study there was not any case with high- grade squamous intraepithelial lesions (HSIL) and squamous cell carcinoma (SCC).

\subsection{Prevalence of HPV Infection}

In all 253 women investigated, 47 cases (18.57\%) were positive for HPV infection; based on the observation of intended band in one or both PCR steps (Figure 1).

The epidemiologic, cytologic and virologic characteristics of HPV positive cases were illustrated in Table 3. Most of the studied population was cytologically normal (85.77\%), among them, $15.66 \%$ were HPV infected, although 36 cases had an abnormal cytology with $36.11 \%$ HPV positive. Totally, 21 cases were cytologically in the ASCUS group (8.3\%), among them, the molecular prevalence of HPV were 38\% (8 cases), although 15 cases had a LSIL cytologic result (5.9\%) with 33.33\% HPV- DNA prevalence (5 cases). An increased chance of HPV infection was found as the severity of cytologic ranged from normal to LSIL.

The distribution of HPV prevalence among different age ranges was shown in Table 4 . This was more outstanding in the younger ages (18 - 25 years). The prevalence of HPV was most prevalent in ages under 20 (33.33\%), and decreased toward aging. it was also high at ages between 30 - 35 years (27.5\%). In the other hand the result of cytology showed an increasing pattern toward aging; the rate of ASCUS was higher at ages more than 40 (14.28\%), and the rate of LISL was high in ages between 36 - 40 (9.3\%).

\subsection{Genotyping of HPV}

The first PCR products of L1 amplification were a 450 base pairs fragment that was utilized for genotyping via direct bidirectional sequencing. In all, 25 cases were randomly selected for sequencing. The obtained sequences were inserted in Blast-n server of NCBI to find the most identical sequences. The sequences directly submitted to gene bank under accession numbers KX421801 to KX421817. The homologous HPV types were referred to Mega software for phylogenic analysis, the result of typing are shown in a phylogenic tree (Figure 2).

The result of sequencing and blast revealed that there were 16 cases out of 25 with HPV type 6 (64\%), 6 cases with 
Table 2. The Prevalence of HPV Among Different Cytological Results ${ }^{a}$

\begin{tabular}{|c|c|c|c|c|}
\hline Cytology state & Number & Age & HPV DNA & P Value \\
\hline Normal cytology & $217(85.77)$ & $36.47 \pm 5.96$ & $34(15.66)$ & $0.05^{\mathrm{b}}$ \\
\hline Total abnormal & $36(14.22)$ & $39.23 \pm 3.02$ & $13(36.11)$ & \\
\hline ASCUS & $21(58.3)$ & $38.1 \pm 4.22$ & $8(38)$ & $0.21^{\mathrm{c}}$ \\
\hline LSIL & $15(41.6)$ & $39.3 \pm 5.1$ & $5(33.33)$ & \\
\hline Total & 253 & $34.47 \pm 5.38$ & $47(18.57)$ & \\
\hline
\end{tabular}

${ }^{\mathrm{a}}$ Values are expressed as No. (\%).

${ }^{\mathrm{b}}$ The prevalence of HPV in the abnormal group was significantly higher than normal group.

${ }^{\mathrm{c}}$ The difference between ASCUS and LISL group was not significant.
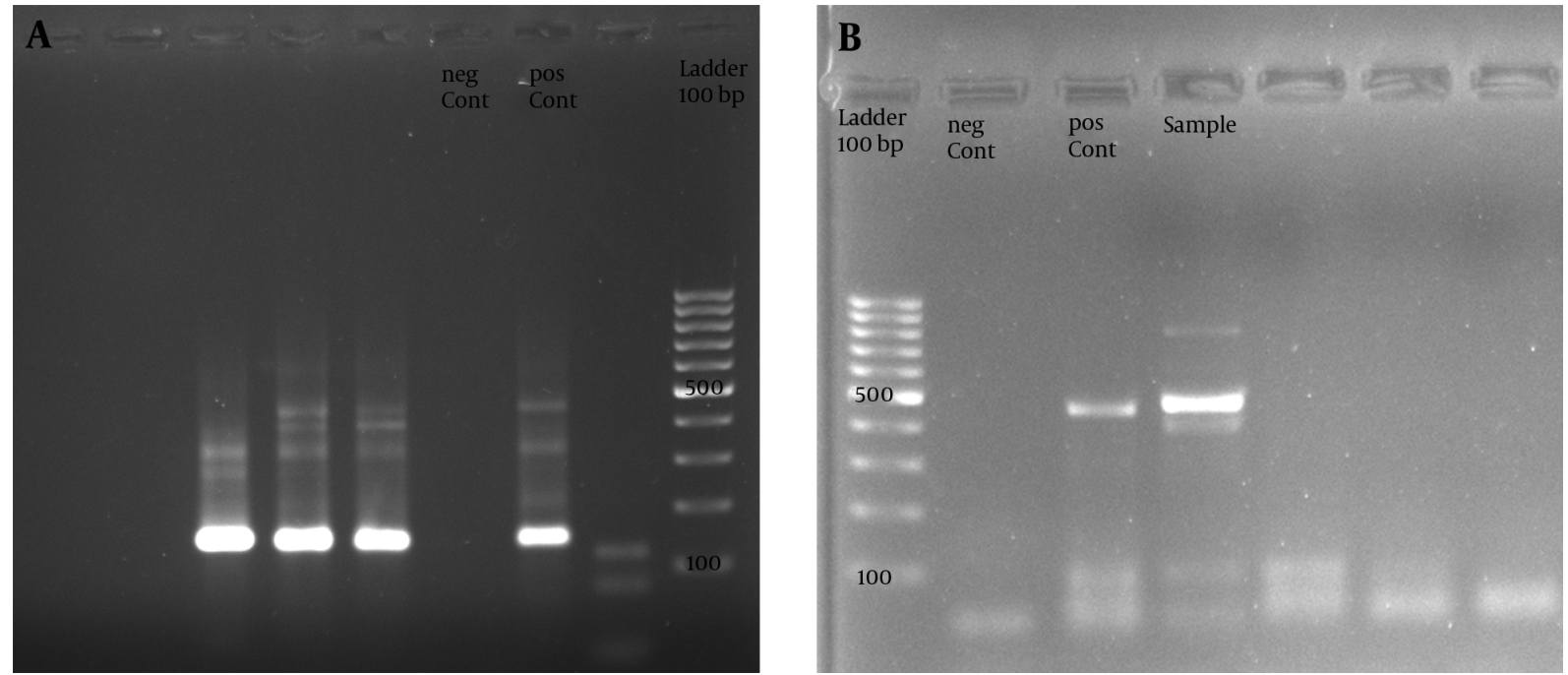

Figure 1. The Gel Image from PCR Product of Nested PCR Using GP Sets Giving a 140 bp Product (A), and Outer Reaction with MY Primers Produced a 450 bp Fragment of L1 Gene (B)

Table 3. The Cytological and Virological Characteristics of HPV Types ${ }^{\mathrm{a}}$

\begin{tabular}{|c|c|c|c|c|c|}
\hline HPV Type & Number & Mean age \pm SD & LSIL & ASCUS & Normal Cytology \\
\hline Low risk types & $23(92)$ & $36 \pm 4.23$ & $2(8.7)$ & $4(17.4)$ & $17(73.91)$ \\
\hline 6 & $16(64)$ & $34.05 \pm 5.66$ & $1(6.25)$ & $3(18.75)$ & $12(75)$ \\
\hline 11 & $6(24)$ & $33.21 \pm 4.05$ & $1(16.66)$ & $1(16.66)$ & $4(66.66)$ \\
\hline 84 & $1(4)$ & 41 & - & - & 1 \\
\hline High risk types & $2(8)$ & $31.5 \pm 3.5$ & $1(50)$ & $1(50)$ & - \\
\hline 16 & $1(4)$ & 28 & 1 & - & \\
\hline 18 & $1(4)$ & 35 & - & 1 & - \\
\hline Total & 25 & $34.2 \pm 6.2$ & $3(12)$ & $5(20)$ & $17(68)$ \\
\hline
\end{tabular}

${ }^{\mathrm{a}}$ Values are expressed as No. (\%).

type 11 (24\%), and types 16, 18 and 84 , each one had just one case (4\%). In this population, HPV 6 were the most preva- lent (64\%) followed by HPV11(20\%). Human papilloma virus types 6 and 11 are low risk types for cervical cancer and $88 \%$ 
Table 4. The Prevalence of HPV According to Age Group and Its Association to Cytology State ${ }^{a}$

\begin{tabular}{|c|c|c|c|c|}
\hline Age Ranges & Number & HPV/Each Group & ASCUS/Each Group & LISL/Each Group \\
\hline$\leq 20$ & $12(4.74)$ & $4(33.33)$ & 0 & 0 \\
\hline $21-25$ & $61(24.11)$ & $12(19.67)$ & $4(6.55)$ & $2(3.27)$ \\
\hline $26-30$ & $69(27.27)$ & $10(14.5)$ & $5(7.24)$ & $4(5.8)$ \\
\hline $31-35$ & $40(15.81)$ & $11(27.5)$ & $4(10)$ & $3(7.5)$ \\
\hline $36-40$ & $43(17)$ & $7(16.27)$ & $4(9.3)$ & $4(9.3)$ \\
\hline $40>$ & $28(11.06)$ & $3(10.71)$ & $4(14.28)$ & $2(7.14)$ \\
\hline Total & 253 & $47(18.57)$ & $21(8.3)$ & $15(5.92)$ \\
\hline
\end{tabular}

${ }^{\mathrm{a}}$ Values are expressed as No. (\%).

of this isolates were of low risks, although there were only $8 \%$ with high risk types. In the normal group only low risk types were detected, although in LSIL and ASCUS groups there were $33.33 \%$ and $20 \%$ high risk type respectively.

\section{Discussion}

Cervical neoplasia is the most common cancer among females in developing countries and is most prevalent in Latin America, Asia and Africa (20). In the pathogenesis of cervical cancer, HPV infection plays central role and this viral infection is believed to be a necessary, but not always sufficient, cause (21). The occurrence of cervical cancer without the involvement of an HPV infection is exceptional (22). Although it is proved that, other cofactors have also significant roles in the development of cervical cancer (23). Recently, prophylactics and therapeutic vaccination has shown promising results for preventing HPV infection as well as for the development of cervical neoplasia (24). However, the production of an effective vaccine requires comprehensive studies of prevalence and genotypes of the virus in different geographical regions of the world.

To the best of our knowledge, this was the first attempt to evaluate the frequency and typing of HPV among women in Southern Khorasan, Iran. Based on PCR, the frequency of HPV in the entire of studied population was $18.75 \%$. It is noteworthy that most part of this population had normal cytology (85.77\%), and the frequency of HPV among them was 15.66 . On the other hand $14.22 \%$ of patients were in the abnormal groups (including $58.3 \%$ in ASCUS and $41.6 \%$ in LSIL). In over all abnormal groups the prevalence of HPV was $36.11 \%$, and in the groups ASCUS and LISL were $38 \%$ and $33.33 \%$ respectively. This result showed an ascending pattern of HPV infection toward abnormalities.

Previous studies showed that there is a low rate of cervical neoplasia in Iran and some other Muslim countries
(25). Moradi in Gorgan showed that $18.1 \%$ of normal and $23 \%$ of abnormal cytology were infected with HPV (26); this rate in Rasht has been reported as $4.08 \%$ and $20 \%$ respectively (27), which are somewhat similar to our Figures. Currently, there are so many epidemiologic studies revealing the state of HPV infection in different parts of Iran. The genital prevalence of HPV among healthy women around the Iran ranged from $5.5 \%$ to $45.4 \%$ with pooled prevalence as $9.4 \%(28,29)$. Previous studies in Iran among different groups of women have shown different prevalence that are affected by many social, economic and methodological approach, however, almost all studies reveal a rather high prevalence of infection among the normal cytology as abnormal, which represents the need and cost effectiveness of prophylactic vaccine. According to a comprehensive review, the worldwide prevalence of HPV was estimated to be 32.1\%; Asia had the highest prevalence as 45.5\%, Europe $15.5 \%$ and Africa $29.6 \%$ (30).

The result of this study determined the highest prevalence of HPV at young ages (33.33\%) and showed a descending rate due to aging (10.71\%), which is in agreement to previous studies $(26,31)$. Interestingly the result of typing of our isolates showed that low risk types of HPV(types 6 and 11) were most prevalent (88\%) while high risk types 16 and 18 were rare ( $8 \%)$. In the normal group there were only low risk types, although in LSIL and ASCUS groups there were $33.33 \%$ and $20 \%$ high risk types respectively. An experiment in Kerman has found similar results; type 6 was most prevalent (49\%) followed by type 16 (10.1\%), and also type 11 (9.2\%) (32). Similar result have been seen recently in men's genital specimen from Tehran; low risk types (53.4\%) and high risks (8.7\%) (33). Although other studies have been reported the high rate of HPV types 16 and $18(31,34,35)$.

It seems that this is the first report of HPV type 84 in Iran which was found in one case in this project. It is reported as a newly characterized HPV type previously known as either MM8 or Pap155 (36) and are common as 


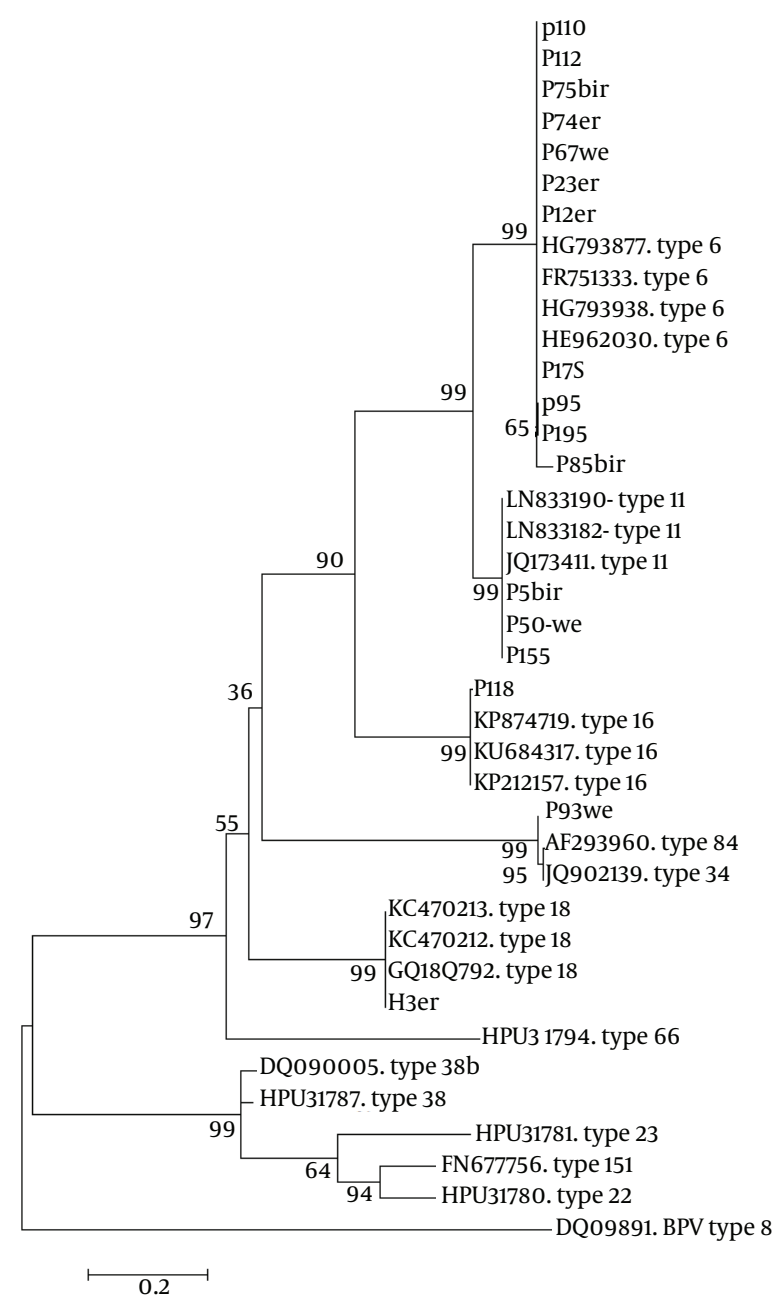

Figure 2. The Maximum Likelihood Phylogenic (ML) Tree of HPV L1 Gene Sequences from Current Isolates in an Alignment with Reference Isolates of Aligned Sequences, Constructed in Mega- 6 Software. Phylogeny Reconstruction Was Done with ML Test and Kimura 2-Parameter Model, Rates Among Sites Was Gamma Distribution, Selected Codon Were $1^{\text {st }}, 2^{\text {nd }}, 3^{\text {rd }}$ and Non- Coding Sites. In Order to Test the Validity of Tree, the Bootstrapping of 1000 Replication Was Used. There Were a Total of 315 Positions in the Final Dataset. The Tree with the Highest Log Likelihood (-3324.8468) Is Shown. The Accession Number of Reference Sequences and HPV Types Were Given in the Front of Branches. The Symbols Except the Accession Numbers Are Sequences of Current Study

a shared HPV type between partners (37). In the current study the positive case for HPV type 84 was a 41 year's old married Iranian woman without any cervical abnormality. Briefly this study represented a high detection rate of genital HPV infection, in respect to normal cytologic in women with normal cytology the low risk types of HPV were prominent. Genotyping is important to determine the risk of high-grade squamous intra epithelial lesions and is useful in management strategies. As HPV infection is causal ele- ment of cervical cancer, this result emphasizes the urgent of molecular HPV diagnosis along with cytopathology examinations and HPV vaccine as well as screening and preventive programs.

\subsection{Conclusion}

This study revealed a partially high frequency of HPV among women with normal and abnormal cytology in Southern Khorasan province of Iran along with most detection rate of low risk HPV types among normal population of this province. Moreover, these results indicate the need for keeping both cytologic and molecular method for HPV detection.

\section{Acknowledgments}

This research was supported by vice chancellor of research, affiliated to Birjand University of Medical Sciences (BUMS). The authors would like to thank Dr. Makvandi and Dr. Rasti from Ahvaz Jundishapur University of Medical Sciences (AJUMS) for kindly donating the positive controls.

\section{Footnotes}

Authors' Contribution: Mohammad Hasan Namaei designed the study and supervised the project. Davod Javanmard performed the experiments, analyzed the data and wrote the manuscript. Mahmoodreza Behravan assisted in experiments, and Fatemeh Haghighi performed the pathology of samples; Masood Ziaee, Alireza Salehabadi, Malaknaz Ghannadkafi and Jamal Mirzaei collected the specimen and data. Gholamreza Sharifzadeh performed the statistical analysis; Nahid Ghanbarzadeh, Zohreh Khazaei, Mahboobeh Zangoie, Narges Naseh, Marzieh Ataei, the women specialists that cooperated in managing patients, collecting Pap smears and patients data.

Conflict of Interests: The authors of this study state that there are no conflicts of interest.

Funding/Support: This work was completely founded and supported by vice chancellor of research in Birjand University of medical sciences (BUMS).

\section{References}

1. Organization WH. . [cited Nov]. Available from: http://www. who. int/mediacentre/factsheets/fs311/en/index. html.

2. Akyar I, Aydin Ö, Yakicier MC, KocagÖZ ZT, İNce Ü, ÜNsal İ. Human papillomavirus prevalence and type in liquid-based cervical samples from Turkish women in a selected risk group. Turkish J Med Sci. 2013;43:963-70. doi: 10.3906/sag-1211-67.

3. Bosch FX, Lorincz A, Munoz N, Meijer CJ, Shah KV. The causal relation between human papillomavirus and cervical cancer.J Clin Pathol. 2002;55(4):244-65. doi: 10.1136/jcp.55.4.244. [PubMed: 11919208]. 
4. Chung CH, Bagheri A, D’Souza G. Epidemiology of oral human papillomavirus infection. Oral Oncol. 2014;50(5):364-9. doi: 10.1016/j.oraloncology.2013.09.003. [PubMed: 24080455].

5. Klug SJ, Hukelmann M, Hollwitz B, Duzenli N, Schopp B, Petry $\mathrm{KU}$, et al. Prevalence of human papillomavirus types in women screened by cytology in Germany. J Med Virol. 2007;79(5):616-25. doi: 10.1002/jmv.20863. [PubMed: 17385693].

6. Daneshvar F, Haghshenas M, Majleci F, Rahimi A. The prevalence and genotype distribution of cervical human papillomavirus DNA in women with normal cytology in north of Iran.Jundishapur JMicrobiol. 2016;10(1) doi: 10.5812/jjm.40823.

7. Roush SW, McIntyre L, Baldy LM. Manual for the surveillance of vaccine-preventable diseases. 4th ed. Atlanta: Department of Health and Human Services; 2008.

8. Munoz N, Bosch FX, de Sanjose S, Herrero R, Castellsague X, Shah KV, et al. Epidemiologic classification of human papillomavirus types associated with cervical cancer. $N$ Engl J Med. 2003;348(6):518-27. doi: 10.1056/NEJMoa021641. [PubMed: 12571259].

9. Giuliano AR, Nyitray AG, Kreimer AR, Pierce Campbell CM, Goodman MT, Sudenga SL, et al. EUROGIN 2014 roadmap: differences in human papillomavirus infection natural history, transmission and human papillomavirus-related cancer incidence by gender and anatomic site of infection. Int J Cancer. 2015;136(12):2752-60. doi: 10.1002/ijc.29082. [PubMed: 25043222].

10. Hegde D, Shetty H, Shetty PK, Rai S, Manjeera L, Vyas N, et al. Diagnostic value of VIA comparing with conventional Pap smear in the detection of colposcopic biopsy proved CIN. Nepal J Obstet Gynaecol. 2011;6(1):712.

11. Nanda K, McCrory DC, Myers ER, Bastian LA, Hasselblad V, Hickey JD, et al. Accuracy of the Papanicolaou test in screening for and follow-up of cervical cytologic abnormalities: a systematic review. Ann Intern Med. 2000;132(10):810-9. doi: 10.7326/0003-4819-132-10-200005160-00009. [PubMed: 10819705].

12. Chao A, Hsu KH, Lai CH, Huang HJ, Hsueh S, Lin SR, et al. Cervical cancer screening program integrating Pap smear and HPV DNA testing: a population-based study. Int J Cancer. 2008;122(12):2835-41. doi: 10.1002/ijc.23441. [PubMed:18338752].

13. Das BC, Murthy NS, Sharma JK, Singh V, Sehgal A, Gopalkrishna V, et al. Human papillomavirus and cervical cancer in indian women. Lancet. 1989;334(8674):1271. doi: 10.1016/s0140-6736(89)91870-9.

14. Arora R, Kumar A, Prusty BK, Kailash U, Batra S, Das BC. Prevalence of high-risk human papillomavirus (HR-HPV) types 16 and 18 in healthy women with cytologically negative Pap smear. EurJ Obstet Gynecol Reprod Biol. 2005;121(1):104-9. doi: 10.1016/j.ejogrb.2004.11.025. [PubMed: 15950365].

15. Munoz N, Bosch FX, Castellsague X, Diaz M, de Sanjose S, Hammouda $\mathrm{D}$, et al. Against which human papillomavirus types shall we vaccinate and screen? The international perspective. Int J Cancer. 2004;111(2):278-85. doi: 10.1002/ijc.20244. [PubMed: 15197783].

16. Bosch FX, Burchell AN, Schiffman M, Giuliano AR, de Sanjose S, Bruni L, et al. Epidemiology and natural history of human papillomavirus infections and type-specific implications in cervical neoplasia. Vaccine. 2008;26 Suppl 10:K1-16. doi: 10.1016/j.vaccine.2008.05.064. [PubMed: 18847553]

17. Nobre RJ, de Almeida LP, Martins TC. Complete genotyping of mucosal human papillomavirus using a restriction fragment length polymorphism analysis and an original typing algorithm. J Clin Virol. 2008;42(1):13-21. doi: 10.1016/j.jcv.2007.11.021. [PubMed: 18304866].

18. Manos MM, Ting Y, Wright DK, Lewis AJ, Broker TR, Wolinsky SM. Use of polymerase chain reaction amplification for the detection of genital human papillomaviruses. Cancer cells. 1989;7(17):209-14.

19. Snijders PJ, van den Brule AJ, Schrijnemakers HF, Snow G, Meijer $\mathrm{CJ}$, Walboomers JM. The use of general primers in the polymerase chain reaction permits the detection of a broad spectrum of human papillomavirus genotypes. J Gen Virol. 1990;71 ( Pt 1):173-81. doi: 10.1099/0022-1317-71-1-173. [PubMed: 2154534].
20. Cutts FT, Franceschi S, Goldie S, Castellsague X, de Sanjose S, Garnett $G$, et al. Human papillomavirus and HPV vaccines: a review. Bull World Health Organ. 2007;85(9):719-26. doi:10.2471/BLT.06.038414. [PubMed: 18026629].

21. Wani K, Nair C. Genetic alterations in cervical cancer. Indian J Exp Biol. 2003;41(8):789-96.

22. Castellsague X, Munoz N. Chapter 3: Cofactors in human papillomavirus carcinogenesis-role of parity, oral contraceptives, and tobacco smoking. J Natl Cancer Inst Monogr. 2003;2003(31):20-8. doi: 10.1093/oxfordjournals.jncimonographs.a003477.

23. Kabat GC, Miller AB, Jain M, Rohan TE. Dietary intake of selected B vitamins in relation to risk of major cancers in women. Br J Cancer. 2008;99(5):816-21. doi:10.1038/sj.bjc.6604540. [PubMed: 18665162].

24. Koutsky LA, Ault KA, Wheeler CM, Brown DR, Barr E, Alvarez FB, et al. A controlled trial of a human papillomavirus type 16 vaccine. $N$ Engl J Med. 2002;347(21):1645-51. doi: 10.1056/NEJMoa020586. [PubMed: 12444178].

25. Khorasanizadeh F, Hassanloo J, Khaksar N, Mohammad Taheri S, Marzaban M, H. Rashidi B , et al. Epidemiology of cervical cancer and human papilloma virus infection among Iranian women - analyses of national data and systematic review of the literature. Gynecol Oncol. 2013;128(2):277-81. doi: 10.1016/j.ygyno.2012.11.032. [PubMed: 23200918].

26. Moradi A, Bakhshandeh Nosrat S, Besharat S. Molecular Epidemiology of High-Risk Types of Human Papillomaviruses $(16,18)$ in PapSmear, the North East of Iran. Iran J Cancer Prev. 2011;4(3):135-40. [PubMed: 26328053].

27. Mohseni Mehran SM, Mansour Ghanaei M, Mojtehadi A. The prevalence of human papilloma virus (HPV) in women using liquid base pap smear in Rasht, northern of Iran. J Clin Diagn Res. 2015;9(7):IC012. doi: 10.7860/JCDR/2015/8206.6139. [PubMed: 26393145].

28. Malary M, Moosazadeh M, Hamzehgardeshi Z, Afshari M, Moghaddasifar I, Afsharimoghaddam A. The prevalence of cervical human papillomavirus infection and the most at-risk genotypes among Iranian healthy women: A systematic review and meta-analysis. Int J Prev Med. 2016;7 doi: 10.4103/2008-7802.181756.

29. Salehi-Vaziri M, Sadeghi F, Hashemi FS, Haeri H, Bokharaei-Salim F, Monavari SH, et al. Distribution of human papillomavirus genotypes in Iranian women according to the severity of the cervical lesion. Iran Red Crescent Med J. 2016;In Press(In Press) doi: 10.5812/ircmj.24458.

30. Vinodhini K, Shanmughapriya S, Das BC, Natarajaseenivasan K. Prevalence and risk factors of HPV infection among women from various provinces of the world. Arch Gynecol Obstet. 2012;285(3):771-7. doi: 10.1007/s00404-011-2155-8. [PubMed: 22159694].

31. Shafaghi B, Jarollahi A, Yousefzadeh B, Ameri A, Moghadam S, Mostafavi M. Human papilloma virus prevalence and types among Iranian women attending regular gynecological visits. Rep Radiother Oncol. 2013;1(2):73-9.

32. Afshar RM, Mollaie HR, Fazlalipour M, Arabzadeh SA. Prevalence and type distribution of human papillomavirus infection using the INNo-Lipa assay, Kerman, Southeast Iran. Asian Pac J Cancer Prev. 2013;14(9):5287-91. doi: 10.7314/APJCP.2013.14.9.5287. [PubMed: 24175815].

33. Salehi-Vaziri M, Sadeghi F, Bokharaei-Salim F, Younesi S, Alinaghi S, Monavari SH, et al. The prevalence and genotype distribution of human papillomavirus in the genital tract of males in Iran. Jundishapur J Microbiol. 2015;8(12) doi: 10.5812/jjm.21912.

34. Jalilvand S, Shoja Z, Nourijelyani K, Tohidi HR, Hamkar R. Metaanalysis of type-specific human papillomavirus prevalence in Iranian women with normal cytology, precancerous cervical lesions and invasive cervical cancer: Implications for screening and vaccination.J Med Virol. 2015;87(2):287-95. doi:10.1002/jmv.24053. [PubMed: 25156655].

35. Zandi K, Eghbali SS, Hamkar R, Ahmadi S, Ramedani E, Deilami I, et al. Prevalence of various human papillomavirus (HPV) genotypes among women who subjected to routine Pap smear test in Bushehr 
city (south west of Iran) 2008-2009. VirolJ. 2010;7:65. doi: 10.1186/1743422X-7-65. [PubMed: 20302680].

36. Terai M, Burk RD. Complete nucleotide sequence and analysis of a novel human papillomavirus (HPV 84) genome cloned by an overlapping PCR method. Virology. 2001;279(1):109-15. doi: 10.1006/viro.2000.0716. [PubMed: 11145894].

37. Widdice LE, Breland DJ, Jonte J, Farhat S, Ma Y, Leonard AC, et al Human papillomavirus concordance in heterosexual couples. J Adolesc Health. 2010;47(2):151-9. doi: 10.1016/j.jadohealth.2010.01.006. [PubMed: 20638007]. 